\title{
Adaptive Forest Fire Spread Simulation Algorithm Based on Cellular Automata
}

\author{
Liyang Sun ${ }^{1}$, Congcong $X u^{1}$, Yanglangxing He ${ }^{1}$, Yanjun Zhao ${ }^{1}$, Yuan $\mathrm{Xu}^{1}$, Xiaoping Rui ${ }^{2, *(D)}$ and Hanwei Xu ${ }^{1, *}$ \\ 1 School of Hydrology and Water Resources, Hohai University, Nanjing 211000, China; \\ sunly@hhu.edu.cn (L.S.); 1809040225@hhu.edu.cn (C.X.); ylxhe@hhu.edu.cn (Y.H.); zhyj@hhu.edu.cn (Y.Z.); \\ 1809040204@hhu.edu.cn (Y.X.) \\ 2 School of Earth Sciences and Engineering, Hohai University, Nanjing 211000, China \\ * Correspondence: ruixp@hhu.edu.cn (X.R.); xuhanwei@hhu.edu.cn (H.X.)
}

check for updates

Citation: Sun, L.; Xu, C.; He, Y.;

Zhao, Y.; Xu, Y.; Rui, X.; Xu, H.

Adaptive Forest Fire Spread

Simulation Algorithm Based on

Cellular Automata. Forests 2021, 12,

1431. https://doi.org/10.3390/

f12111431

Academic Editor: Olga Viedma

Received: 7 August 2021

Accepted: 17 October 2021

Published: 20 October 2021

Publisher's Note: MDPI stays neutral with regard to jurisdictional claims in published maps and institutional affiliations.

Copyright: (c) 2021 by the authors. Licensee MDPI, Basel, Switzerland. This article is an open access article distributed under the terms and conditions of the Creative Commons Attribution (CC BY) license (https:// creativecommons.org/licenses/by/ $4.0 /)$.

\begin{abstract}
The popular simulation process that uses traditional cellular automata with a fixed time step to simulate forest fire spread may be limited in its ability to reflect the characteristics of actual fire development. This study combines cellular automata with an existing forest fire model to construct an improved forest fire spread model, which calculates a speed change rate index based on the meteorological factors that affect the spread of forest fires and the actual environment of the current location of the spread. The proposed model can adaptively adjust the time step of cellular automata through the speed change rate index, simulating forest fire spread more in line with the actual fire development trends while ensuring accuracy. When used to analyze a forest fire that occurred in Mianning County, Liangshan Prefecture, Sichuan Province in 2020, our model exhibited simulation accuracy of $96.9 \%$, and kappa coefficient of 0.6214 . The simulated fire situation adapted well to the complex and dynamic fire environment, accurately depicting the detailed fire situation. The algorithm can be used to simulate and predict the spread of forest fires, ensuring the accuracy of spread simulation and helping decision makers formulate reasonable plans.
\end{abstract}

Keywords: forest fire spread simulation; adaptive; cellular automata; remote sensing; forest fire disaster

\section{Introduction}

Forest fires are characterized by destruction and a propensity to suddenly change, jeopardizing people's safety and property [1]. Accordingly, decision makers need an efficient and accurate simulation of forest fire spread to help them suppress fires. Accurate and specific simulations can enable decision makers to quickly understand the current fire state and intuitively access fire spreading trends, thereby providing scientific support for formulating efficient fire suppression programs.

Forest fires occur under the combined action of weather and geographical conditions, and the phenomenon is a complex physical and chemical process. Forest fire spread simulation is based on the theoretical forest fire spread model, which uses reasonable computer simulation algorithms to predict the dynamic development process of forest fires [2].

Many different models have attempted to offer insights into forest fire spread. They are traditionally divided into three categories by a modelling mechanism: theoretical physical models, empirical models, and semi-empirical models. The physical model is best represented by the Fons model [3] and Albini model [4]. The empirical models include the elliptical model [5], McArthur model [6], and Canada forest fire model [7]. The semiempirical models notably include the Rothermel model [8], Van Wagner model [9], and Wang model [10].

A forest fire spread simulation algorithm uses raster or vector format data to show the spread of forest fires. Commonly used methods include the Huygens wave propagation [11], cellular automata (CA) method [12], penetration theory [13,14], and fractal 
theory [15], with the CA method also including boundary interpolation and the maze algorithm [16]. These various algorithms have all contributed to the development of algorithms for simulating forest fire spread.

Among these methods, the CA model is of particular interest for this study. This model is defined in the discrete space of the dynamic system, with the cell state at the next time affected by itself and the neighboring cell state at the current time. Conceptualizing forest fire spread as a spatiotemporal dynamic change process is compatible with the CA model [17]. Currently, simulating forest fire spread through the CA model has become an increasingly popular research area, with Eskandari et al. combining the CA model with the Alexandridis model to simulate and predict some forest fires in Iran, comparing the simulation results with the actual fire boundaries to qualitatively evaluate the model [18] Similarly, Rui et al. artificially improved the temporal and spatial consistency of the forest fire spread model by combining the CA model with the Wang Zhengfei model, adding time correction coefficients to increase the accuracy of forest fire spread predictions [19]. Furthermore, Mutthulakshmi et al. used the CA model to analyze the factors that affect fire spread and to determine which factors play key roles in various forest fire spread situations [20].

Forest fires are generally difficult to predict, so that the CA model must be tweaked to fit the specific time and place of a fire. Vahidnia et al. proposed a new CA model, using artificial intelligence tools such as the adaptive neuro-fuzzy inference system (ANFIS) and the genetic algorithm (GA) to optimize the CA model's transition rules [21]. Zheng et al. integrated the extreme learning machine with the traditional forest fire CA framework to propose a new model that describes the effects of wind velocity on fire spread patterns [22]. To simulate a real-time interactive crown fire spread, Liu et al. introduced a new CA model based on the reaction and radiation physical equations, verifying the model's function [23]. Previous literature has combined forest fire spread models and the CA model with a fixed time step, focusing on improving the spatial and temporal consistency of forest fire spread simulations or analyzing the main factors that influence forest fire spread. However, no study has used the CA model with a variable time step to adaptively simulate forest fire spread under different fire states.

Forest fires are affected by complex topographical factors, weather, and the nature of the combustible material involved in the process of spreading. Owing to the non-uniformity of these factors, the spread of forest fires is non-uniform, with fires alternating between being severe and subdued [24]. Despite the dynamic nature of actual fires, the existing CA model's time steps for forest fire spread simulation are fixed. The CA model is used to simulate forest fire spread at equal intervals. When the fire is strong, the overfire area for one time step becomes extremely large, so that the detailed fire state cannot be reflected accurately; as a result, decision makers may be unable to make accurate fire-fighting decisions in a timely manner. When the fire is weak, the overfire area for one time step becomes extremely small, rendering changes in fire state insignificant. Such a short time step is unnecessary and may waste computer resources.

Fire state is determined by various factors, including terrain, wind direction, and combustible properties. Forest fire spread speed is a comprehensive response under the combined influence of factors including local topography, wind speed, and combustible properties [24]. Changes in fire state are caused by these complex environments and are intuitively reflected in forest fire spread. In this study, the speed change rate index is constructed to reveal changes in fire state, allowing adaptive adjustment of the time step of the CA model. When wind speed is high, slope is steep, or other contributing factors are present, a forest fire spreads more quickly, with the time step decreasing through the speed change rate index to provide more details about the fire spread. Accordingly, based on the time-corrected Wang Zhengfei model [19], this study proposes an adaptive CA forest fire spread algorithm that takes into account the heterogeneity of weather, terrain, and vegetation factors. The speed change rate index is used to adjust the time step by comparing changes in forest fire spread dynamically, informing decisions. 


\section{Algorithm Development}

This method obtains the spatial distribution of combustibles from remote sensing data, extracting topographical factors from the digital elevation model (DEM). Then, based on the revised Wang Zhengfei model [19], the speed change rate index is introduced to adjust the time step and produce an adaptive CA algorithm. This algorithm can be used to simulate forest fire spread, while characterizing the effects of the current environment on a forest fire, providing decision makers with details about the spread with guaranteed accuracy, as Figure 1 shows.

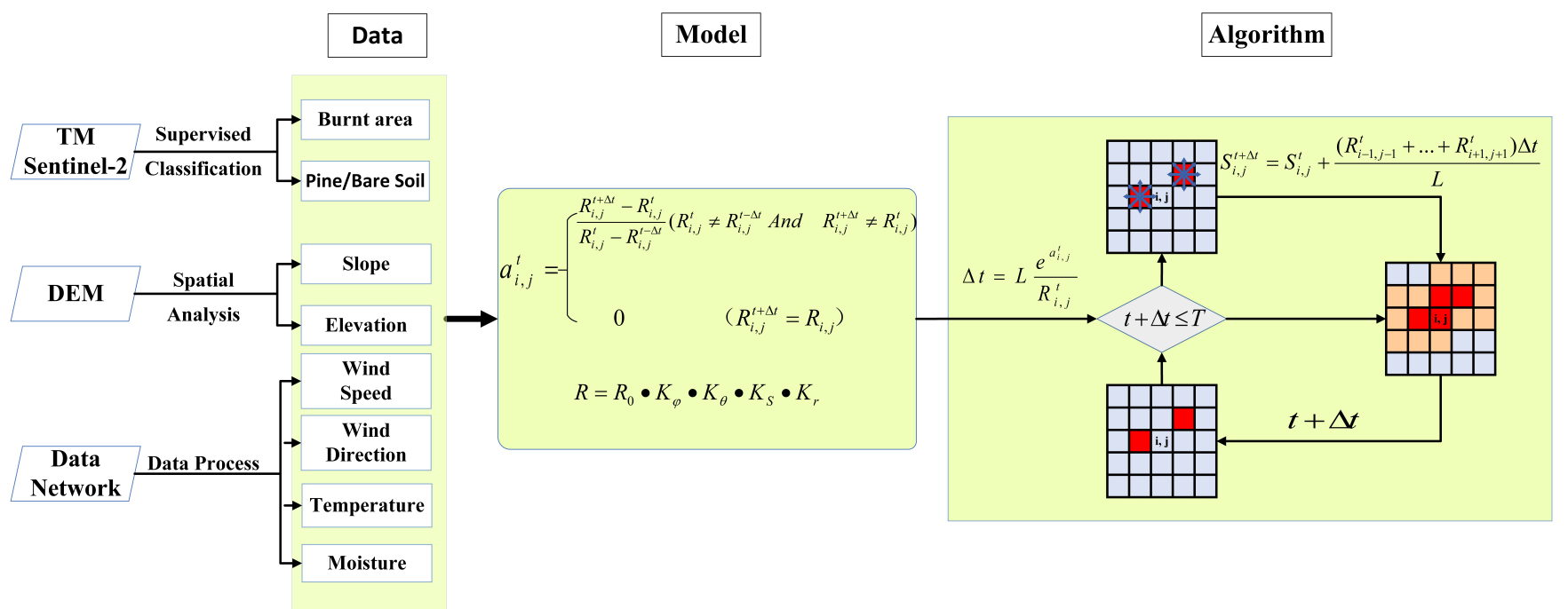

Figure 1. Design of an adaptive forest fire spread simulation algorithm based on cellular automata.

\subsection{Revised Wang Zhengfei Model}

Rui et al. revised Wang Zhengfei model [19], which takes into account weather, topography, combustibles, and temporal consistency, using a time correction coefficient to ensure consistency between the stimulated fire and the real fire. The time correction coefficient was obtained based on repeated experiments.

Based on this model, to characterize the effects of current environment on forest fires, a speed change rate index was introduced for adjusting the time step of the CA model, allowing the forest fire simulation to adjust to the complex environment, producing the spread details.

$$
\begin{gathered}
R=R_{0} \cdot K_{\varphi} \cdot K_{\theta} \cdot K_{S} \cdot K_{r}, \\
R_{0}=a \cdot T+b \cdot W+c \cdot(100-R H)-d, \\
W=\operatorname{Int}\left(\frac{v}{0.836}\right)^{\frac{2}{3}}, \\
K_{\varphi}=e^{0.1783 \cdot v \cdot \cos \varphi,} \\
K_{\theta}=e^{3.553 \cdot g \cdot \tan (1.2 \cdot \theta),}
\end{gathered}
$$

where $R$ is the forest fire spread speed $(\mathrm{m} / \mathrm{min}), R_{0}$ is the initial speed of the forest fire spread ( $\mathrm{m} / \mathrm{min}), K_{\varphi}$ is the wind coefficient, $K_{\theta}$ is the terrain factor, $K_{S}$ is the combustible index (obtained from a lookup table) [10], $K_{r}$ is the time correction coefficient, $a=0.03$, $b=0.05, c=0.01, d=0.3, T$ is the ambient air temperature $\left({ }^{\circ} \mathrm{C}\right), W$ is the wind level, Int indicates a set integer, $R H$ is the air relative humidity $(\%), v$ is the wind speed $(\mathrm{m} / \mathrm{s}), \varphi$ is the angle between the wind direction and the fire spread direction, $h$ is the slope, and $g$ is the direction of the hill -1 for uphill and -1 for downhill.

In Equation (1), the forest fire spread speed comprises the initial fire speed, wind, terrain, combustibles, and time correction coefficient. The initial fire speed is determined by the daily-scale environmental factors, which can be considered constant during a time 
step. Because the time correction coefficient is revised to be a constant, changes in fire spread speed are decided mainly by wind, terrain, and combustibles on the time step scale.

\subsection{Adaptive Geographic Cellular Automata Algorithm}

The CA model is a changeable system that composes a cell and cell space. The discrete, finite state cell evolves in the cell space following certain rules [25], which can be abstracted as $\langle Z n, S, N, f\rangle$, namely $\langle$ n-dimensional cell space, state, number of neighborhoods, state transition rules $>$.

In the forest fire spread geographical cellular automata algorithm, fire units with different geographical burning conditions are located in the geographical cell space. As the discrete time progresses, the state of each cell changes depending on its own state and its neighbors' states, following the forest fire spreading rules. This procedure is shown in Figure 2 .

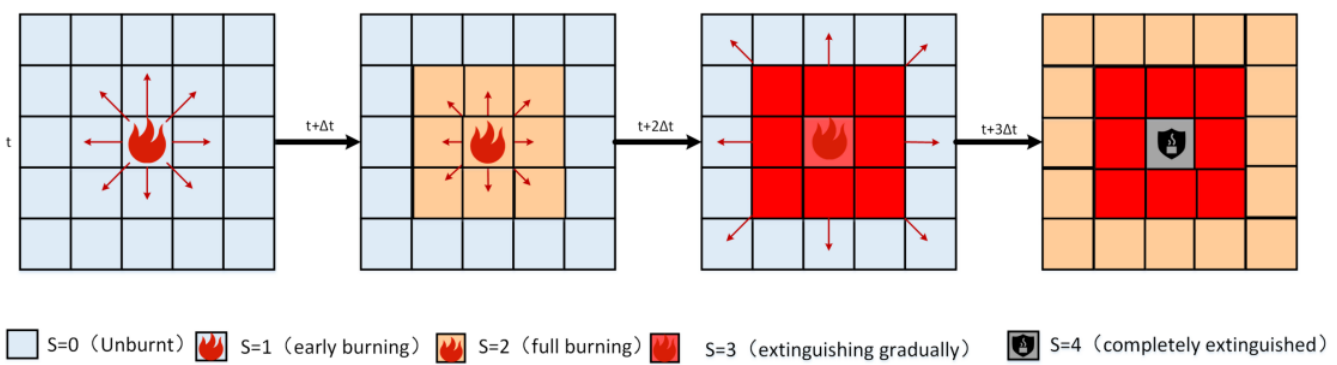

Figure 2. Cellular state change procedure.

The grid pixels can be used to represent the cell size. Because the remote sensing data grid size was set to $30 \mathrm{~m}$, the forest fire spread geographical cellular automata algorithm used a $30 \mathrm{~m}$ grid as the unit space, with the pixel values representing the cell states defined as: $S=0$ (unburnt), $S=1$ (early burning), $S=2$ (full burning, capable of igniting surrounding cells), $S=3$ (extinguishing gradually), and $S=4$ (completely extinguished).

After the fire condition is input, the simulated forest fire begins to spread, with any cell having a state value of 2 able to ignite the surrounding cells, causing the forest fire to continue spreading. The change in the time dimension is not continuous: after time step $\Delta t$, the cell state at the next time $(t+\Delta t)$ is calculated according to the cell state at the current time $(t)$ and its neighbors' states. The state conversion rule is designed to imitate the burning process of actual trees. For example, when cell state is 0 (unburnt), if a cell has state 1 (early burning), then the state value is next calculated using the following formula: When cell state is 1 (early burning), it will next become 2 (full burning). When cell state is 2 (full burning) and neighbor's states all equal or exceed 2 (full burning), the focal cell state will next become 3 (extinguishing gradually). When cell state is 3 (extinguishing gradually), the state value will next become 4 (completely extinguished).

When the fire is becoming stronger, its spread will accelerate, so to provide more detail about the predicted spread of the fire, the time step should decrease. When the fire becomes smaller, its spread will decelerate, so to prevent wasting computer resources, the time step should increase. To reflect the fire trend, the speed change rate index was constructed to represent increments of forest fire spread, with the adaptive geographic cellular automata algorithm constructed as follows.

$$
\begin{gathered}
S_{i, j}^{t+\Delta t}=S_{i, j}^{t}+\frac{\left(R_{i-1, j-1}^{t}+\ldots+R_{i+1, j+1}^{t}\right) \Delta t}{L}\left(R_{i, j}^{t}=0\right), \\
a_{i, j}^{t}=\left\{\begin{array}{c}
R_{i, j}^{t+\Delta t}-R_{i, j}^{t}\left(R_{i, j}^{t+\Delta t}=R_{i, j}^{t}\right) \\
0\left(R_{i, j}^{t+\Delta t}=R_{i, j}^{t}\right)
\end{array},\right.
\end{gathered}
$$




$$
\Delta t=\frac{\Delta t_{0}}{e^{a_{i, j}^{t}}}
$$

where $S_{i, j}^{t}$ is the cell state, $R_{i, j}^{t}$ is the forest fire spread speed (m/min), $L$ is the cell size $(\mathrm{m})$, $a_{i, j}^{t}$ is the speed change rate index, $\Delta t$ is the time step, and $\Delta t_{0}$ is the initial time step.

The cell state at the next time instance is determined primarily by the cell state at the current time, spreading speed of neighboring cells, cell size, and time step $\Delta t$.

The speed change rate index represents changes in the fire's spread speed at adjacent time steps, reflecting the current environment's effects on its spread. It is determined by the complex in the environment where the fire spreads and is expressed in Equation (7).

Time step $\Delta t$ depends on the initial time step and speed change rate index $a_{i, j}^{t}$. The initial time step is fixed at $1 \mathrm{~h}$, and the speed change rate index reflects changes in the fire's intensity.

During a forest fire's spread, higher wind speeds, more flammable cover, and slope are all conducive to the spread of forest fires, so that the speed change rate index will exceed zero, with the time step reducing adaptively. Consequently, the cell state should be calculated more frequently, providing more detailed predicted spread results. If the current environment inhibits the spread of forest fires, the speed change index will be less than zero, so the time step should increase, which can effectively demonstrate a slowly changing trend of forest fire spread.

\section{Experiment}

\subsection{Research Area}

To verify the algorithm, the forest fire in Mianning County, Sichuan Province, from 7-11 May 2020, was chosen as a case study (Figure 3). Mianning County is located in the southwest of Sichuan Province, has a mild weather, and is mainly composed of mountainous landform.

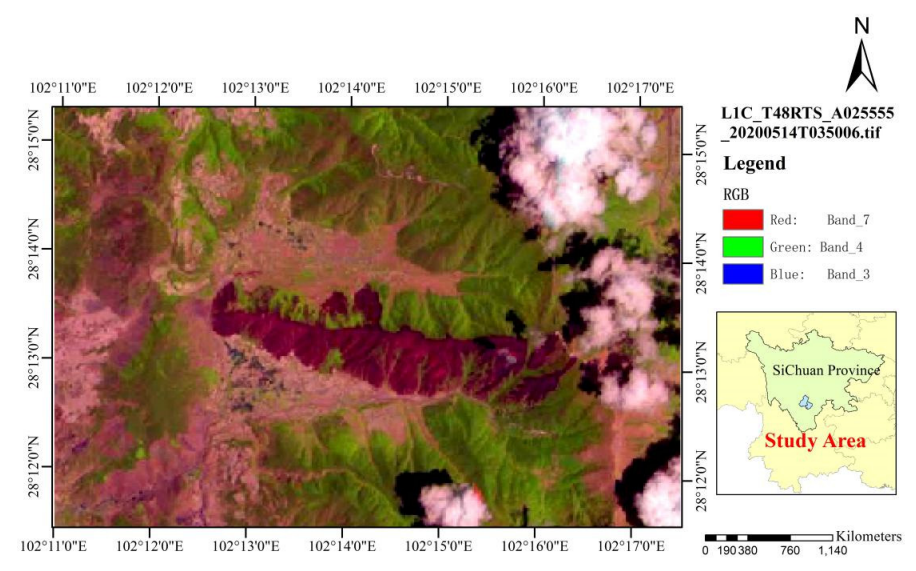

Figure 3. Mianning forest fire area, 2020.

\subsection{Data and Data Processing}

For this study, the hourly Mianning County meteorological dataset was downloaded from the China Meteorological Data Sharing Service Network, and the DEM data of ASTER GDEM version 2, Landsat ${ }^{\mathrm{TM}}$, ETM+, and Sentinel 2 were downloaded from the US Geological Survey Earth Probe. The time range of the meteorological dataset was 6-12 May 2020, and the time frequency was $1 \mathrm{~h}$.

The vegetation coverage in the study area was mainly pine trees. The distribution of combustibles was extracted from the Landsat 8 image for 13 March, using the maximum likelihood supervised classification method. Finally, the study area was divided into two categories: pine and bare soil. Figure 4 shows the combustibles distribution map. 


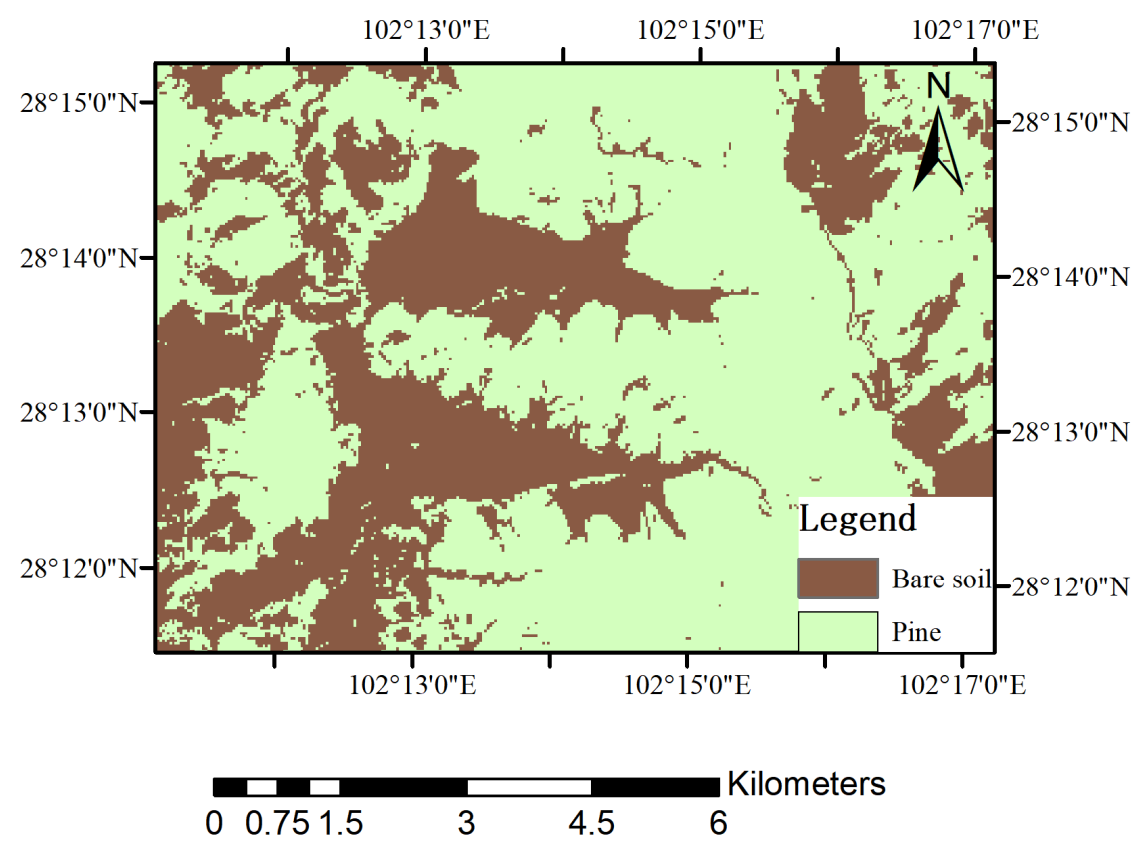

Figure 4. Combustibles distribution map.

To obtain the initial input data for the fire's spread, the burnt area and the actively burning area was extracted from the Landsat ETM+ image for 8 May, which was visually interpreted based on various spectral and thermal characteristics as well as smoke. These were used as the input data for the fire spread stimulation, as Figure 5a shows. It is not possible to download two images from the same sensor between 6 May 2020 and 12 May 2020, so the data of the fire's end situation were obtained through Sentinel-2 image visual interpretation for 14 May, which was used to verify the accuracy of the simulated fire, as Figure $5 b$ shows.
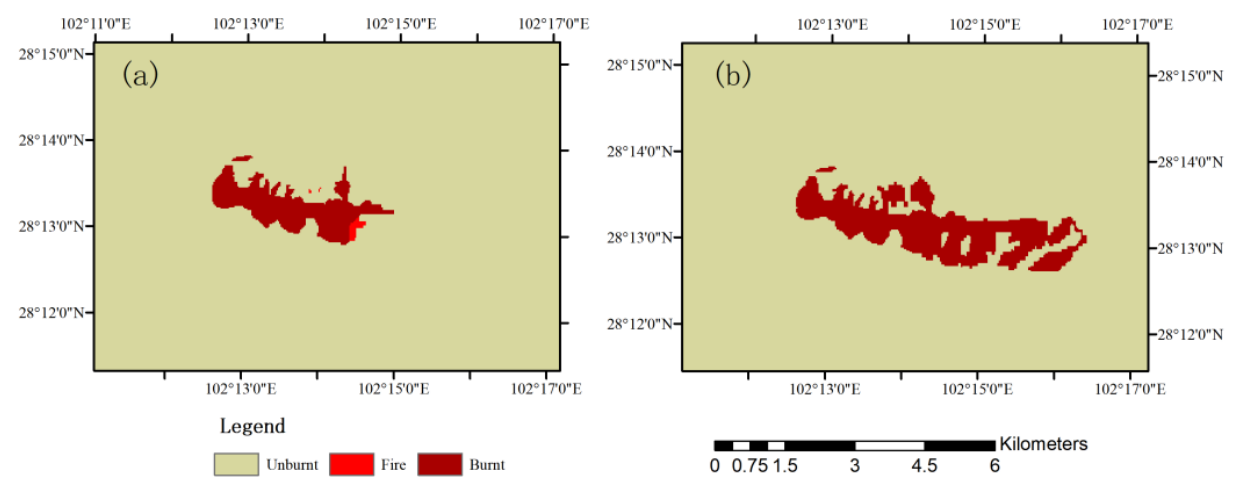

Figure 5. Extracted fire situation map: (a) initial and (b) ultimate.

The DEM was also used to extract terrain information, such as slope and aspect. The raster image was cropped, color-synthesized, stripped, interpreted, and resampled uniformly to achieve a resolution of $30 \mathrm{~m}$.

\subsection{Simulation Results and Accuracy}

To obtain the best time correction coefficient, the simulation results and the actual fire situation were combined. The time correction coefficient was adjusted several times, and the time consistency was best when $K_{r}=1 / 25$, which was used to guarantee the time consistency between the simulated and actual fires.

A forest fire spread simulation was conducted for Mianning County, Liangshan Prefecture, Sichuan Province in May 2020, which adapted to the complex real-world environment. To evaluate the simulation accuracy, the remote sensing image of 14 May was 
superimposed on the simulation result simultaneously, as Figure 6 shows. The shape and position of the simulation result and the actual fire situation were consistent. The kappa coefficient was 0.6214 , indicating a high degree of consistency, and the accuracy was $96.9 \%$, indicating a high degree of accuracy.
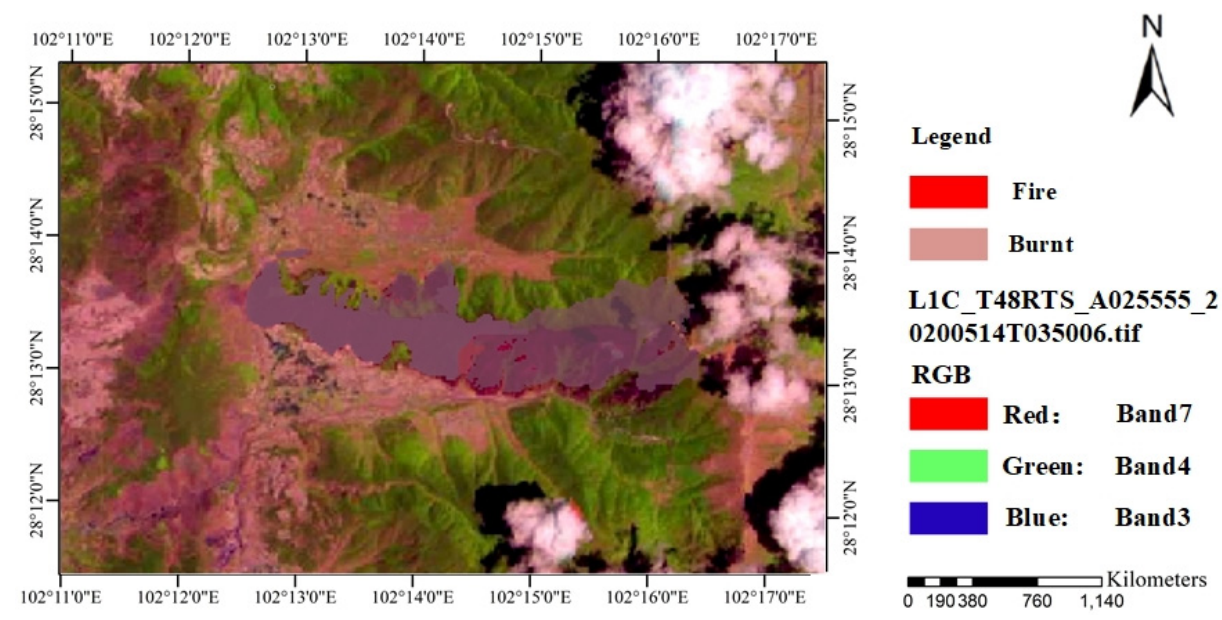

Figure 6. Simulation result graph.

On the right-hand side, the upper part of the simulation result was larger than that in the actual fire situation, perhaps because actual fire suppression focused on the northeast side of the fire. (This simulation did not consider the influence of the fire suppression plans actually employed.)

\subsection{Adaptive Forest Fire Spread Simulation under Different Conditions}

The time step of traditional CA model was fixed at $1 \mathrm{~h}$, as was the initial time step of the adaptive CA model. With different factors influencing forest fire spread, the simulation results of the two CA models were compared separately. Because there was a single combustible species in the study area, simulation results for different combustible material types were not analyzed.

\subsubsection{Wind Speed}

The meteorological dataset of the study area for 6 May 2021 to 12 May 2021 was analyzed, and the maximum wind speed recorded between 11:00 and 12:00 on 9 May 2021 was $8 \mathrm{~m} / \mathrm{s}$. The traditional and adaptive CA models were each used to simulate the spread of forest fires from 11:00 to 12:00 on 9 May.

Figure $7 \mathrm{a}, \mathrm{d}$ show the fire states of the traditional CA model for this time. Predicted forest fire spread occurred primarily in the northeastern, eastern, and northern directions of the region. High wind speed caused the predicted forest fire to spread quickly, with the burnt area changing significantly between single time steps. An extremely large time step made details of the predicted spread unavailable.

The adaptive CA model was used to simulate the forest fire spread, so that the time step decreased as the speed of the forest fire's spread increased. Figure $7 \mathrm{~b}, \mathrm{c}$ show the intermediate predicted spreading details: from 11:00 to 11:22, the predicted spread occurred mainly in the northeastern direction of the fire line at a greater rate, whereas the burnt area did not change significantly in the eastern and northern directions of the fire line. Between 11:22 and 11:39, the predicted spread speed was the same in all three directions. From 11:39 to 12:00, the predicted spread of forest fire occurred primarily in the east of the fire line. 

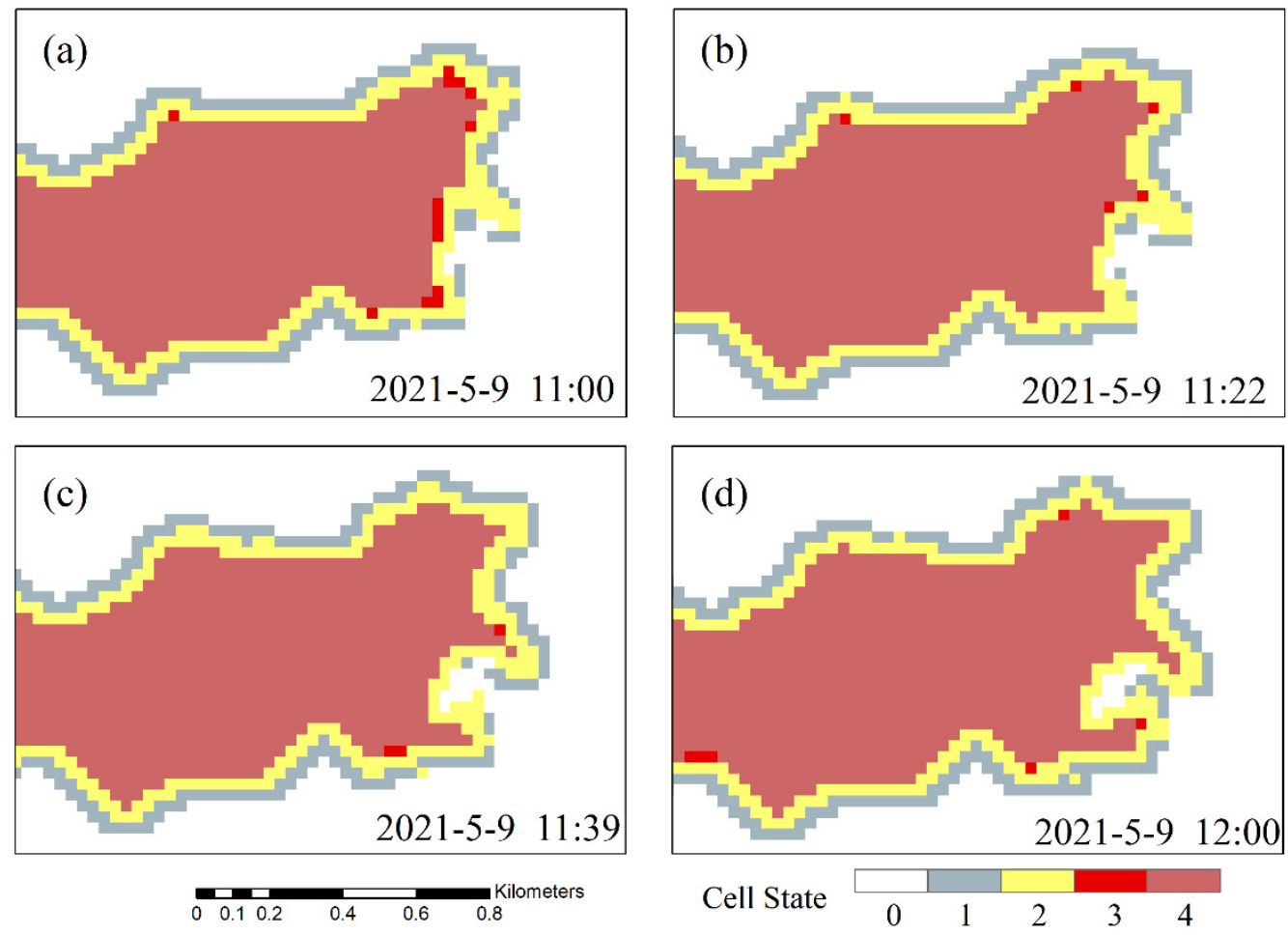

Figure 7. Predicted forest fire spread simulation map for 2021.5.9 11:00-12:00: (a) traditional CA model simulation graph for 9 May 2021, at 11:00; (b) adaptive CA model simulation graph for 9 May 2021, at 11:22; (c) adaptive CA model simulation graph for 9 May 2021, at 11:39; (d) traditional CA model simulation graph for 9 May 2021, at 12:00.

\subsubsection{Slope}

The slope of the fire line location from 19:00 to 20:00 on 8 May 2021 was large. The traditional CA model was used to simulate fire spread from 19:00 to 20:00 on 8 May 2021, producing the results shown in Figure 8a,d. Comparison of these maps revealed that the predicted spread of forest fires occurred directly in the south and southeast areas, with large variations in burnt area.

The adaptive CA model was used to simulate fire spread during the same period, with the time step decreasing as the speed of the fire's spread increased, providing the specific predicted spread details shown in Figure $8 \mathrm{~b}, \mathrm{c}$. The predicted spread of forest fire southeast of the fire line occurred from 19:00 to 19:24 and from 19:38 to 20:00, with the predicted spread of the fire directly south of the fire line from 19:24 to 19:38.

\subsubsection{Relationship between Aspect and Wind Direction}

Based on the analysis of the meteorological dataset and the aspect of the study area, the slope was consistent with the wind direction on 8 May 2021, from 15:00 to 16:00.

Similarly, the traditional CA model was used to simulate fire spread from 15:00 to 16:00 on 8 May 2021, with the fire states shown in Figure 9a,d. The predicted forest fire spread occurred in all directions of the fire line.

During this $1 \mathrm{~h}$, the time step of the adaptive CA model decreased as predicted fire spread accelerated. Details of the changes to the burnt area are shown in Figure $9 \mathrm{~b}, \mathrm{c}$. Between 15:00 and 15:12, the predicted forest fire spread quickly, mainly in the eastern direction of the fire line. Between 15:12 and 15:28, the predicted forest fire spread mainly in the northern and southwestern directions of the fire line, with the spread rate decreasing and the time step became larger. Between 15:28 and 16:00, the fire line continued to spread southwest and east. These predicted spread details could aid decision makers in developing a reasonable fire suppression plan. 

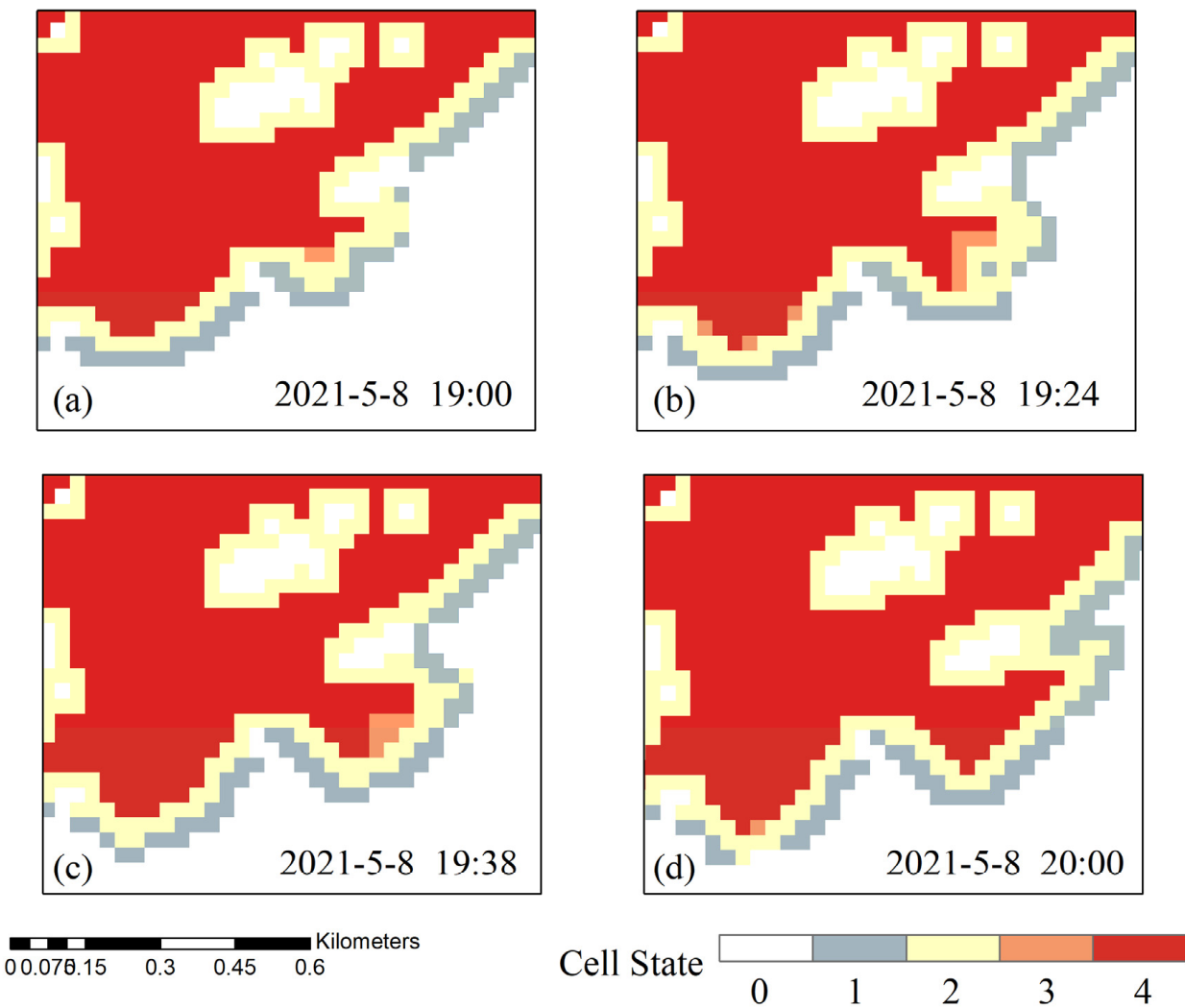

Figure 8. Predicted forest fire spread simulation map for 8 May 2021 19:00-20:00: (a) traditional CA model simulation graph for 8 May 2021, at 19:00; (b) adaptive CA model simulation graph for 8 May 2021, at 19:24; (c) adaptive CA model simulation graph for 8 May 2021, at 19:38; (d) traditional CA model simulation graph for 8 May 2021, at 20:00.
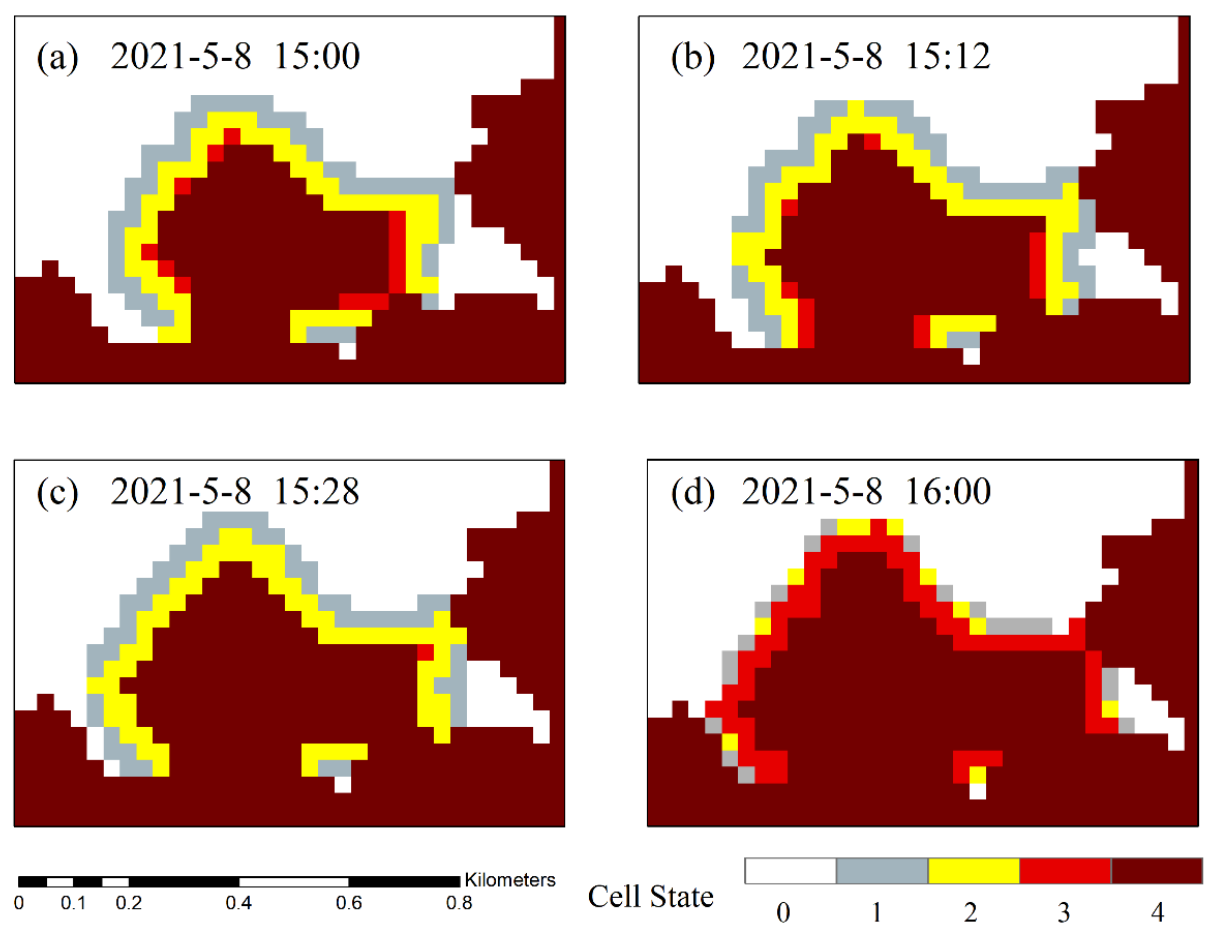

Figure 9. Predicted forest fire spread simulation map for 2021.5.8 15:00-16:00: (a) traditional CA model simulation graph for 8 May 2021, at 15:00; (b) adaptive CA model simulation graph for 8 May 2021, at 15:12; (c) adaptive CA model simulation graph for 8 May 2021, at 15:28; (d) traditional CA model simulation graph for 8 May 2021, at 16:00. 


\section{Discussion}

The forest fire spread simulations in this study have much the same accuracy as those in the previous literature [18-23], but here, the speed change rate index has been constructed to adjust the time step of the CA model. When fire speed is rapid, the time step decreases adaptively using the speed change rate index, providing more details about the fire's predicted spread. Conversely, when the fire's speed is slow, the time step increases adaptively using the speed change rate index, conserving computer resources. Such an approach may help decision makers formulate more reasonable plans.

The example analysis in this study shows the advantages of this method: (1) the time step is calculated exponentially, with its value controlled within a certain range. For example, in this study, the range of the speed change rate index of forest fire spread in Sichuan Province was $[-2,1]$; hence, the range of the time step was calculated as $\left[\frac{\Delta t_{0}}{e^{2}}, e \cdot \Delta t_{0}\right]$, using the formula, so that the value of the time step could be adjusted within a reasonable range (2). When the fire becomes stronger, the time step decreases adaptively to provide as many details about predicted fire spread as possible. When the fire's rate decreases, the time step increases adaptively to avoid wasting computer resources, and the time step will not be too large, thereby providing sufficient details on the predicted forest fire spread. However, this method has certain limitations: (1) forest fire spread simulations are influenced by many factors [24], so that, although the adaptive method in this study could reproduce the observed final fire perimeter, the universality of the method has not been verified, and whether it is suitable for forest fire spread in other areas is uncertain. (2) In this study, the effect of the initial time step on the forest fire spread simulation was not considered. Although the initial time step of $1 \mathrm{~h}$ is suitable for the example fire simulation, it might not be applicable to other fires. Studying ways of determining the appropriate initial time step for a particular fire would be worthwhile.

In addition, because the terrain data and vegetation data are constant over long period, whereas meteorological data change rapidly, high-time-frequency meteorological data are needed to improve the accuracy of forest fire spread simulations and provide more details about fire spread. Owing to the presence of only a single type of combustible in the study area, this study did not analyze the simulation results of the adaptive CA model under various combustible conditions. Nor was the adaptive CA model verified by abundant fire samples. In the future, to improve the accuracy of the adaptive CA model and analyze the factors driving forest fire, analysis should include more fire samples and use machine learning methods.

Remote sensing images with high spatial and temporal resolution are essential for simulating forest fire accurately. Drone technology has been widely used in forest fire simulations, providing real-time images of forest fire spread. Specifically, it can this technology help in constructing more accurate forest fire spread models and can also be used to verify predicted forest fire spread [26]. In the future, application of drone technology to forest fire spread simulation should also be considered.

\section{Conclusions}

This study addressed the problem whereby using a fixed time step, as in the traditional CA algorithm may limit decision makers' ability to make reasonable plans. An adaptive forest fire spreading simulation algorithm was proposed, that couples the revised Wang Zhengfei model with the CA model. This algorithm takes into account the influence of meteorological factors and the changeable forest fire environment, constructing a speed change rate index that adjusts the time step adaptively, so that spread simulation adapts to complex real-world environments, providing more details about forest fire spread when fire is intense, while ensuring simulation accuracy. The main findings are as follows:

1. With a view to ensuring simulation accuracy, the adaptive forest fire spread simulation algorithm, based on cellular automata, can automatically adjust the time step so that forest fire spread can adapt to dynamic real-world environments, conforming to 
actual fire changes, and better simulate results. The experimental simulation accuracy was $96.9 \%$, and the kappa coefficient was 0.6214 .

2. In the traditional CA model, in which the time step is fixed, when a fire is large, producing large changes in the burnt area within one time step, it is impossible to know the details of the fire surge in all directions on the fire line, which may hinder emergency decision making. By contrast, the adaptive CA model that uses a variable time step can provide more details about fire spread for decision-makers. When wind speed is high, slope is large, or wind direction is consistent with slope direction, fire spreads faster, with the time step of the adaptive CA model decreasing to better reflect the details of its spread.

Author Contributions: L.S. downloaded some of the data, processed the data, proposed the new model, and wrote the original manuscript; C.X. reprocessed the data, created the algorithm design map, and helped build the new model; Y.H. helped download the data, contributed to the data analysis, and created the research area map; Y.Z. extracted the combustibles distribution from the remote sensing image, created the map of combustibles distribution, and conducted some investigation; Y.X. created the map of the procedure for cellular state change and read related articles; X.R. helped devise the model, guided the use of the model throughout, and reviewed and edited the manuscript; H.X. contributed to the guide for using of the new model. All authors have read and agreed to the published version of the manuscript.

Funding: This paper was supported by the National Key Research and Development Plan of China (No. 2019YFC1804304), the National Natural Science Foundation of China (Grant No. 41771478) and the Fundamental Research Funds for Central Universities (Grant No. 2019B02514).

Institutional Review Board Statement: Not applicable.

Informed Consent Statement: Not applicable.

Data Availability Statement: Hourly Mianning County meteorological dataset available at https: / / data.cma.cn/ (accessed on 6 August 2021), "DEM data of ASTER GDEM version 2, Landsat TM, ETM+ and Sentinel 2" available at http:/ / earthexplorer.usgs.gov / (accessed on 6 August 2021).

Conflicts of Interest: The authors have no conflicts of interest to declare.

\section{References}

1. Kan, Z.; Ma, D.; Zhang, H. Characteristics of forest fire and suppression countermeasures in Sichuan forest region. For. Sci. Technol. 2004, 2, 29-31.

2. Papadopoulos, G.D.; Pavlidou, F.N. A comparative review on wildfire simulators. IEEE Syst. J. 2011, 5, 233-243. [CrossRef]

3. Fons, W.L. Analysis of fire spread in light forest fuels. J. Agric. Res. 1946, 72, 93-121.

4. Albini, F.A. Spot Fire Distance from Burning Trees: A Predictive Model. Intermountain Forest and Range Experiment Station, Forest Service; US Department of Agriculture: Washington, DC, USA, 1979.

5. Anderson, D.H.; Catchpole, E.A.; De Mestre, N.J.; Parkes, T. Modelling the spread of grass fires. ANZIAM J. 1982, 23, 451-466. [CrossRef]

6. Mcarthur, A.G. Weather and Grassland Fire Behavior; Forestry and Timber Bureau, Department of National Development, Commonwealth of Australia: Canberra, Australia, 1966; p. 100.

7. Stocks, B.J.; Lawson, B.D.; Alexander, M.E.; Van Wagner, C.E.; Lynham, T.J.; Dube, D. The Canadian forest fire danger rating system: An overview. For. Chron. 1989, 65, 258-265. [CrossRef]

8. Rothermel, R.C. A Mathematical Model for Predicting Fire Spread in Wildland Fuels; Intermountain Forest \& Range Experiment Station, Forest Service, US Department of Agriculture: Washington, DC, USA, 1972; Volume 115.

9. Van Wagner, C.E. Prediction of crown fire behavior in two stands of jack pine. Can. J. For. Res. 1993, 23, 442-449. [CrossRef]

10. Wang, Z. Current forest fire danger rating system. J. Nat. Disasters 1992, 1, 39-44. [CrossRef]

11. Glasa, J.; Halada, L. On elliptical model for forest fire spread modeling and simulation. Math. Comput. Simul. 2008, 78, 76-88. [CrossRef]

12. Karafyllidis, I.; Thanailakis, A. A model for predicting forest fire spreading using cellular automata. Ecol. Model. 1997, 99, 87-97. [CrossRef]

13. Broadbent, S.R.; Hammersley, J.M. Percolation processes. I: Crystals and mazes. Math. Proc. Camb. Philos. Soc. 1957, 53, 629-641. [CrossRef]

14. Wolfgang Von, N.; Alexander, B. Dynamic simulation of forest fires. Can. J. For. Res. 1988, 18, 807-814. [CrossRef]

15. Zhu, Q.; Rong, T.; Sun, R. A case study on fractal simulation of forest fire spread. Sci. China 2000, 43, 104-112. [CrossRef] 
16. Ding, Z.; Song, K.; Wang, Z.; Tang, X.; Dong, Z.; Jia, M.; Shao, T. Contrastive analysis of algorithms of the forest fire spreading simulation based on ArcGIS engine. J. Univ. Chin. Acad. Sci. 2014, 31, 640-646.

17. Huang, H.G.; Zhang, X.L.; Wang, L. Simulation of forest fire spread based on a 3D-surface cellular automata model. J. Beijing For. Univ. 2005, 27, 94-97. [CrossRef]

18. Eskandari, S. Application of a CA-based model to predict the fire front in hyrcanian forests of Iran. Arab. J. Geosci. 2016, 9, 688. [CrossRef]

19. Rui, X.; Hui, S.; Yu, X.; Zhang, G.; Wu, B. Forest fire spread simulation algorithm based on cellular automata. Nat. Hazards J. Int. Soc. Prev. Mitig. Nat. Hazards 2018, 91, 309-319. [CrossRef]

20. Mutthulakshmi, K.; Wee, M.R.E.; Wong, Y.C.K.; Lai, J.W.; Koh, J.M.; Acharya, U.R.; Cheong, K.H. Simulating forest fire spread and fire-fighting using cellular automata. Chin. J. Phys. Taipei 2020, 65, 642-650. [CrossRef]

21. Vahidnia, M.H.; Alesheikh, A.A.; Behzadi, S.; Salehi, S. Modeling the spread of spatio-temporal phenomena through the incorporation of ANFIS and genetically controlled cellular automata: A case study on forest fire. Int. J. Digit. Earth 2013, 6, 51-75. [CrossRef]

22. Zheng, Z.; Huang, W.; Li, S.; Zeng, Y. Forest fire spread simulating model using cellular automaton with extreme learning machine. Ecol. Model. 2017, 348, 33-43. [CrossRef]

23. Liu, Y.; Liu, H.; Zhou, Y.; Sun, C. Spread vector induced cellular automata model for real-time crown fire behavior simulation. Environ. Model. Softw. 2018, 108, 14-39. [CrossRef]

24. Guo, F.; Wang, G.; Su, Z.; Liang, H.; Wang, W.; Lin, F.; Liu, A. What drives forest fire in Fujian, China? Evidence from logistic regression and random forests. Int. J. Wildland Fire 2016, 25, 505. [CrossRef]

25. Collin, A.; Bernardin, D.; Sero-Guillaume, O. A physical-based cellular automaton model for forest-fire propagation. Combust. Sci. Technol. 2011, 183, 347-369. [CrossRef]

26. Tang, L.; Shao, G. Drone remote sensing for forestry research and practices. J. For. Res. 2015, 26, 791-797. [CrossRef] 